\title{
Cystic fibrosis, aminoglycoside treatment and acute renal failure: the not so gentle micin
}

\author{
Detlef Bockenhauer • Martin J. Hug • Robert Kleta
}

Received: 26 August 2008 /Revised: 30 September 2008 / Accepted: 2 October 2008 / Published online: 13 November 2008

(C) IPNA 2008

\begin{abstract}
Aminoglycosides have a wide spectrum of gramnegative anti-bacterial activities and are available at low cost, which makes them commonly used drugs, especially for patients with cystic fibrosis (CF), who often suffer from chronic lung infections from Pseudomonas aeruginosa. Unfortunately, this treatment seems to have resulted in an increased incidence of acute renal failure (ARF) in patients with $\mathrm{CF}$. A recent case-control study investigated risk factors for ARF in CF patients and suggested intravenous use of gentamicin as the prime culprit. Moreover, in most cases, at least one other risk factor, such as CF-related diabetes, pre-existing renal failure, dehydration or concurrent use of other nephrotoxic drugs, was present. We comment on the renal handling of aminoglycosides and the possible mechanisms of toxicity, as well as strategies for risk minimisation.
\end{abstract}

Keywords Cystic fibrosis - Aminoglycoside - Gentamicin . Acute renal failure $\cdot$ Children

D. Bockenhauer $(\bowtie) \cdot$ R. Kleta

Paediatric Nephrology, Great Ormond Street Hospital,

Great Ormond Street,

London WC1 3JH, UK

e-mail: bocked@gosh.nhs.uk

M. J. Hug

Pharmacy, University Hospital Freiburg,

Freiburg, Germany

R. Kleta

Centre for Nephrology, University College London,

London, UK

\section{Introduction}

Aminoglycosides (AGs) are commonly used in the treatment of gram-negative infections, because of their wide spectrum of anti-bacterial activities and comparatively low costs. They have good efficacy against Pseudomonas aeruginosa, which makes them especially useful in patients with cystic fibrosis (CF), who typically suffer from chronic lung infection from this bacterium. However, the use of AGs has possible side effects. In a recent case-control study Smyth et al. identified AG use as a key risk factor for the development of acute renal failure (ARF) in CF patients [1]. The study was based on a previous report by the same group in which they had identified 24 confirmed cases of ARF in CF patients, establishing the incidence of ARF, somewhat vaguely defined as "raised plasma creatinine for age", as approximately 100-times higher in children with CF (4.6-10.1 cases/10.000 CF patients per year) than the background incidence $(7.5$ cases $/ 1,000,000$ per year) in the UK [2]. Of these 24 cases, 21 were associated with acute AG exposure. The nephro- (and oto-) toxicity of aminoglycosides has long been known, but how does it occur and what can be done to prevent this complication?

\section{Mechanism of toxicity}

Several mechanisms have been proposed for AG toxicity, including disruption of lysosomal function, induction of apoptosis via the calcium-sensing receptor and interference with protein synthesis (reviewed in [3]). The key mechanism of toxicity, however, appears to be related to its bacteriostatic effect: AGs bind to bacterial ribosomes, reducing fidelity of transcription and thus leading to errors in bacterial protein synthesis (reviewed in [4]). Human 
mitochondrial ribosomes bear structural resemblance to bacterial ribosomes, consistent with the bacterial ancestry of mitochondria [5]. This makes mitochondrial function particularly prone to AG toxicity.

\section{Aminoglycosides and the kidney}

AGs are non-protein bound drugs and, thus, are freely filtered by the glomerulus. Re-uptake can occur via megalin-mediated endocytosis in the proximal tubule [6]. This leads to increased concentration of AGs in proximal tubule cells and, therefore, the particular susceptibility of the kidney to AG toxicity [7]. Thus, mitochondrial dysfunction in the proximal tubule is the expected consequence of AG toxicity, and this is, indeed, concordant with the clinical findings: AG-induced kidney failure is typically non-oliguric, with evidence of proximal tubular dysfunction and damage (reviewed in [8]) and occasionally frank renal Fanconi syndrome [9]. Occasionally, more distant tubular segments are affected with a Bartter-like syndrome [10] or renal magnesium wasting [11].

An interesting point in the paper by Smyth et al. is the fact that not only acute AG use (within a week of ARF onset) but also previous administration in the preceding year were identified as risk factors. Duration of aminoglycoside therapy and cumulative exposure had previously been identified as risk factors for nephrotoxicity in the general population [12]. However, with the limitations of a case-control study, it is impossible to determine whether AGs may actually cause subclinical long-term damage, predisposing to subsequent $\mathrm{ARF}$, or whether more frequent AG exposure just reflects more severely ill patients.

\section{Prevention of aminoglycoside-induced acute renal failure}

So, what can be done to prevent AG-induced ARF? Avoidance of AG use would clearly eliminate this complication, but, given their antibacterial efficacy, their long track record of use and their low cost, this would not be practicable in clinical reality. Yet other measures can help.

\section{Dose monitoring}

Toxicity is dose-dependent and related to glomerular kidney function. In their previous paper, Smyth's group showed that trough levels in their $\mathrm{CF}$ patients exceeded the recommended value of $2 \mathrm{mg} / 1$ in nine out of 21 patients with ARF [2], demonstrating the importance of meticulous dose monitoring.

\section{Dosage frequency}

Once-daily administration of aminoglycoside has been shown to have good clinical efficacy in CF patients [13] but less toxicity than two- or three-times daily administration in animals [14] as well as humans [15]. This makes sense, as megalin-mediated AG uptake in the proximal tubule is saturable. Thus, the high plasma levels after a single dose may exceed the uptake capacity of the proximal tubule, so that, overall, less AG enters the proximal tubule cells. Yet, 19 of the 21 patients received three-times daily dosing [2].

\section{Mode of administration}

In order to avoid systemic toxicity, one can administer AGs in nebulised form to treat pulmonary infections, which results in minimal systemic absorption yet satisfactory clinical efficacy for both gentamicin and tobramycin [16, 17]. Indeed, concurrent nebulised AG did not confer an increased risk for ARF in the study by Smyth et al. [1]. However, ARF in the context of inhaled tobramycin has been reported [18]. Thus, drug level monitoring may be advisable, even with this form of administration, especially before commencement of intravenous therapy of the same drug, to assess baseline systemic concentration.

\section{Choice of aminoglycoside}

In their paper Smyth et al. demonstrated an association of ARF with exposure in the previous year to gentamicin, but not tobramycin [1]. Interestingly, they did not examine the choice of AG for the acute administration, but their previous survey showed that $18 / 21$ cases of ARF were in the context of acute gentamicin exposure and $3 / 21$ with tobramycin [2]. A concomitant survey of prescribing practices showed that, actually, more CF centres prescribed tobramycin than gentamicin, suggesting that the increased incidence of ARF with gentamicin reflected true increased nephrotoxicity of this drug rather than just prescribing patterns. And, indeed, there is previous evidence for increased toxicity of gentamicin in the general population [19]. Moreover, resistance to gentamicin has been found in the majority of Pseudomonas aeruginosa identified in patients with $\mathrm{CF}$ in the UK and many other countries, making it a poor choice not only because of side effects [20,21]. 


\section{Risk factors for acute renal failure}

Despite renal expression of cystic fibrosis transmembrane regulator (CFTR), the kidney itself seems to be primarily unaffected [22]. Nevertheless, patients with CF do have an increased risk for kidney-related problems such as stone disease or ARF, because of secondary complications: increased salt loss through sweat promotes dehydration [23]; intestinal fat malabsorption due to pancreatic enzyme deficiency leads to hyperoxaluria [24]; moreover, diabetes mellitus-related nephropathy [25] and chronic infections with potential immune complex deposition [26] are well recognised risk factors. Some of these obviously become more prominent with the increasing life expectancy of $\mathrm{CF}$ patients. Smyth et al. also investigated the presence of such risk factors, specifically pre-existing renal disease, concurrent use of other nephrotoxic drugs, CF-related diabetes mellitus, sepsis and dehydration. At least one of those risk factors was present in 18 of the 24 patients but only 7 of the 42 controls [1]. This is not surprising and highlights the cumulative effect of various nephrotoxic pathways. Several of those risk factors may simply potentiate the toxicity by decreasing glomerular filtration rate (GFR), as the resultant, prolonged, slow and steady delivery of AG to the luminal re-uptake receptors will enhance AG re-uptake. This could explain, for instance, the additive toxicity of non-steroidal anti-inflammatory drugs, which should be avoided. Lung infections and subsequent deterioration of lung function are still the one and major problem in most patients affected by $\mathrm{CF}$, and concomitant administration of several potentially nephrotoxic antibiotics such as colistin, vancomycin and aminoglycosides is sometimes required to treat acute exacerbations of chronic lung infections. However, this should be carefully considered with respect to nephrotoxicity. The use of pre-drug hydration has not been studied systematically for AG treatment. However, this has been shown to be extremely successful for other nephrotoxic drugs such as cisplatin and makes intuitive sense also for AG use [27]. Thus, once-daily dosing regimens as well as GFR-appropriate dosing, checked by drug level measurements, and adequate hydration should be a prerequisite for AG treatment, particularly for children with CF.

\section{Genetic susceptibility to aminoglycoside toxicity}

The ototoxicity of $A G$ has been linked to a particular mitochondrial $12 \mathrm{~S}$ rRNA gene mutation, m.1555A $>\mathrm{G}$, which facilitates the binding of AGs to mitochondrial ribosomes [28]. Whilst there are no reports of concomitant renal failure in those patients with aminoglycoside-induced deafness, there have been no studies investigating this, and there is no reason to exclude a priori pathogenicity of this mutation in the kidney. If proven, a simple genetic test could identify those patients at risk for toxicity and in whom AG use should be considered carefully.

\section{Conclusion}

There has been a steady improvement in the life expectancy of patients with CF over the past decades [29-31]. Part of this improvement comes from the establishment of early and improved diagnostics [32, 33] and the aggressive treatment of chronic lung infections, often using AGs. The study by Smyth et al. highlights that this approach is not without risk. Importantly, it shows potential strategies that minimise this risk, consistent with previous studies: that co-administration of other nephrotoxic medications should be avoided; adequate hydration should be ensured, and dosing should be once daily with meticulous attention to drug levels. Moreover, given the resistance pattern to gentamicin and its apparent increased nephrotoxicity, the use of tobramycin, instead of gentamicin, seems justified. Recommendations for the more frequent use of tobramycin also have implications for the treatment of patients that do not suffer from CF.

Studies are needed to investigate a potential link between the mitochondrial m.1555A $>\mathrm{G}$ mutation and nephrotoxicity and whether a test for this mutation could identify patients at particular risk. Unfortunately, by the time the nephrologist is called to the bedside, the damage has usually already been done. This emphasises the need to communicate these issues with our colleagues providing care to $\mathrm{CF}$ patients. Significant progress in the treatment of patients with CF has been accomplished. Further improvements are possible; a multi-disciplinary approach, by pulmonologists, nephrologists, pharmacists and others, can make this happen. Studies like the one by Smyth et al. will help to ensure a continued and needed discussion.

\section{References}

1. Smyth A, Lewis S, Bertenshaw C, Choonara I, McGaw J, Watson A (2008) Case-control study of acute renal failure in patients with cystic fibrosis in the UK. Thorax 63:532-535

2. Bertenshaw C, Watson AR, Lewis S, Smyth A (2007) Survey of acute renal failure in patients with cystic fibrosis in the UK. Thorax 62:541-545

3. Pannu N, Nadim MK (2008) An overview of drug-induced acute kidney injury. Crit Care Med 36:S216-S223

4. Spahn CM, Prescott CD (1996) Throwing a spanner in the works: antibiotics and the translation apparatus. J Mol Med 74:423439 
5. Wirmer J, Westhof E (2006) Molecular contacts between antibiotics and the $30 \mathrm{~S}$ ribosomal particle. Methods Enzymol 415:180-202

6. Moestrup SK, Cui S, Vorum H, Bregengård C, Bjørn SE, Norris K, Gliemann J, Christensen EI (1995) Evidence that epithelial glycoprotein 330/megalin mediates uptake of polybasic drugs. J Clin Invest 96:1404-1413

7. Vandewalle A, Farman N, Morin JP, Fillastre JP, Hatt PY, Bonvalet JP (1981) Gentamicin incorporation along the nephron: autoradiographic study on isolated tubules. Kidney Int 19:529-539

8. Mingeot-Leclercq MP, Tulkens PM (1999) Aminoglycosides: nephrotoxicity. Antimicrob Agents Chemother 43:1003-1012

9. Gainza FJ, Minguela JI, Lampreabe I (1997) Aminoglycosideassociated Fanconi's syndrome: an underrecognized entity. Nephron $77: 205-211$

10. Chou CL, Chen YH, Chau T, Lin SH (2005) Acquired bartter-like syndrome associated with gentamicin administration. Am J Med Sci 329:144-149

11. Finton CK, Bjorkland S, Zaloga GP, Uddin DE, Chernow B (1983) Gentamicin-induced hypomagnesemia. Am Surg 49:576578

12. Bertino JS Jr, Booker LA, Franck PA, Jenkins PL, Franck KR, Nafziger AN (1993) Incidence of and significant risk factors for aminoglycoside-associated nephrotoxicity in patients dosed by using individualized pharmacokinetic monitoring. J Infect Dis 167:173-179

13. Smyth A, Tan KHV, Hyman-Taylor P, Mulheran M, Lewis S, Stableforth D, Knox A; TOPIC Study Group (2005) Once versus three-times daily regimens of tobramycin treatment for pulmonary exacerbations of cystic fibrosis - the TOPIC study: a randomised controlled trial. Lancet 365:573-578

14. Reiner NE, Bloxham DD, Thompson WL (1978) Nephrotoxicity of gentamicin and tobramycin given once daily or continuously in dogs. J Antimicrob Chemother 4 [Suppl A]:85-101

15. Rybak MJ, Abate BJ, Kang SL, Ruffing MJ, Lerner SA, Drusano GL (1999) Prospective evaluation of the effect of an aminoglycoside dosing regimen on rates of observed nephrotoxicity and ototoxicity. Antimicrob Agents Chemother 43:1549-1555

16. Twiss J, Byrnes C, Johnson R, Holland D (2005) Nebulised gentamicin - suitable for childhood bronchiectasis. Int $\mathrm{J}$ Pharm 295:113-119

17. Geller DE, Pitlick WH, Nardella PA, Tracewell WG, Ramsey BW (2002) Pharmacokinetics and bioavailability of aerosolized tobramycin in cystic fibrosis. Chest 122:219-226

18. Hoffmann IM, Rubin BK, Iskandar SS, Schechter MS, Nagaraj SK, Bitzan MM (2002) Acute renal failure in cystic fibrosis: association with inhaled tobramycin therapy. Pediatr Pulmonol 34:375-377

19. Smith CR, Lipsky JJ, Laskin OL, Hellmann DB, Mellits ED, Longstreth J, Lietman PS (1980) Double-blind comparison of the nephrotoxicity and auditory toxicity of gentamicin and tobramycin. N Engl J Med 302:1106-1109
20. Pitt TL, Sparrow M, Warner M, Stefanidou M (2003) Survey of resistance of Pseudomonas aeruginosa from UK patients with cystic fibrosis to six commonly prescribed antimicrobial agents. Thorax 58:794-796

21. Kresken M, Hafner D, Schmitz FJ, Wichelhaus T (2006) Resistenzsituation bei klinisch wichtigen Infektionserregern gegenüber Antibiotika in Deutschland und im mitteleuropäischen Raum. Bericht über die Ergebnisse einer multizentrischen Studie der Arbeitsgemeinschaft Empfindlichkeitsprüfungen \& Resistenz der Paul-Ehrlich-Gesellschaft für Chemotherapie e.V. aus dem Jahre 2004. Antiinfectives Intelligence

22. Kleta R, Brune T, Harms E (1999) Cystic fibrosis and metabolic alkalosis in children - revisited. Miner Electrolyte Metab 25:210

23. Ballestero Y, Hernandez MI, Rojo P, Manzanares J, Nebreda V, Carbajosa H, Infante E, Baro M (2006) Hyponatremic dehydration as a presentation of cystic fibrosis. Pediatr Emerg Care 22:725727

24. Hoppe B, von Unruh GE, Blank G, Rietschel E, Sidhu H, Laube N, Hesse A (2005) Absorptive hyperoxaluria leads to an increased risk for urolithiasis or nephrocalcinosis in cystic fibrosis. Am J Kidney Dis 46:440-445

25. Andersen HU, Lanng S, Pressler T, Laugesen CS, Mathiesen ER (2006) Cystic fibrosis-related diabetes: the presence of microvascular diabetes complications. Diabetes Care 29:2660 2663

26. Abramowsky CR, Swinehart GL (1982) The nephropathy of cystic fibrosis: a human model of chronic nephrotoxicity. Hum Pathol 13:934-939

27. Rossi R, Kleta R, Ehrich JH (1999) Renal involvement in children with malignancies. Pediatr Nephrol 13:153-162

28. Prezant TR, Agapian JV, Bohlman MC, Bu X, Oztas S, Qiu WQ, Arnos KS, Cortopassi GA, Jaber L, Rotter JI, Shohat M, FischelGhodsian N (1993) Mitochondrial ribosomal RNA mutation associated with both antibiotic-induced and non-syndromic deafness. Nat Genet 4:289-294

29. Dodge JA, Lewis PA, Stanton M, Wilsher J (2007) Cystic fibrosis mortality and survival in the UK: 1947-2003. Eur Respir J 29:522-526

30. Bellis G, Cazes MH, Parant A, Gaimard M, Travers C, Le Roux E, Ravilly S, Rault G (2007) Cystic fibrosis mortality trends in France. J Cyst Fibros 6:179-186

31. Slieker MG, Uiterwaal CS, Sinaasappel M, Heijerman HG, van der Laag J, van der Ent CK (2005) Birth prevalence and survival in cystic fibrosis: a national cohort study in the Netherlands. Chest 128:2309-2315

32. Schuler D, Sermet-Gaudelus I, Wilschanski M, Ballmann M, Dechaux M, Edelman A, Hug M, Leal T, Lebacq J, Lebecque P, Lenoir G, Stanke F, Wallemacq P, Tümmler B, Knowles MR (2004) Basic protocol for transepithelial nasal potential difference measurements. J Cyst Fibros 3 [Suppl 2]:151-155

33. Hug MJ, Tummler B (2004) Intestinal current measurements to diagnose cystic fibrosis. J Cyst Fibros 3 [Suppl 2]:157-158 